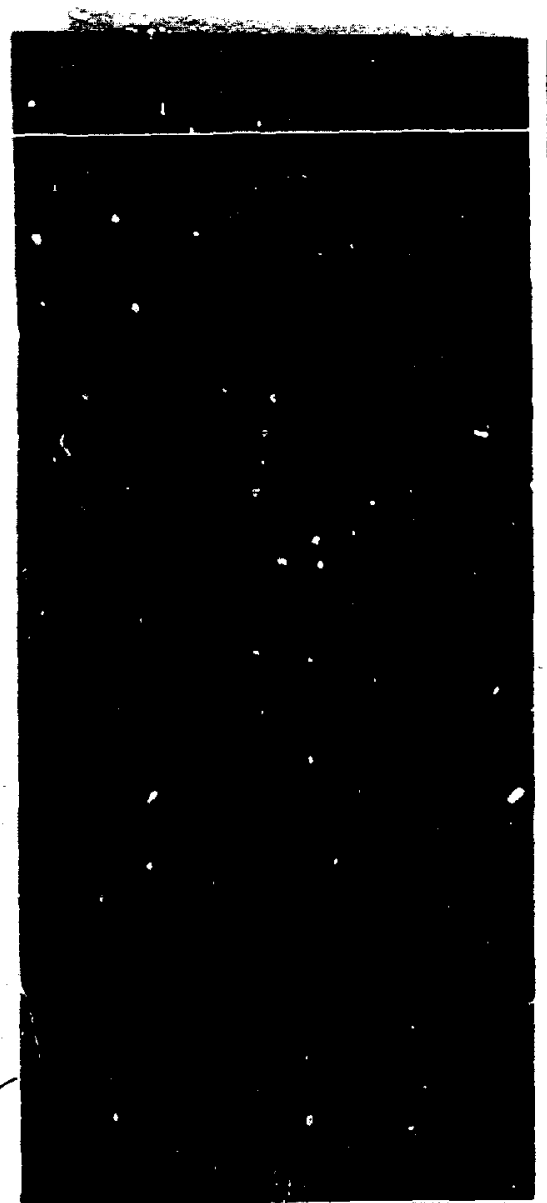

\title{
MASTER
}

ORNL/こSD/TM-92

\section{Feedback Control Modeling of Plasma Position and Current During Intense Heating in ISX-B}
L. A. Charlton
D. W. Swain
G. it. Neilson

Access to the information in this report is !imited to those indicatied on the distribution list and to U.S. Government Agencies and their Contiactors.

\section{OAK RIDGE NATIONAL YABORATORY} .OPERATED BY UNION CARBIOE CORPORATION - FOR THE DEPARTMENT OF ENERGY 
Contract No. W-7405-eng-26

COMPUIER SCIENCES DIVISION

FEEDEACK CONTROL MODELING OF PLASMA POSITION AND CURRENT

DURING INTENSE HEATING IN ISX-B

L. A. Charlton

Computer Sciences Division

D. H. Swain

G. H. Neilson

Fusion Energy Division

Sponsor: D. W. Swain

Originator: L. A. Charlton

Date Published - Aug'tst 1979

NOTICE

This document cont-ins information of a preliminary nature.

It is subject to evision or correction and therefore does

not represent a final repoit.

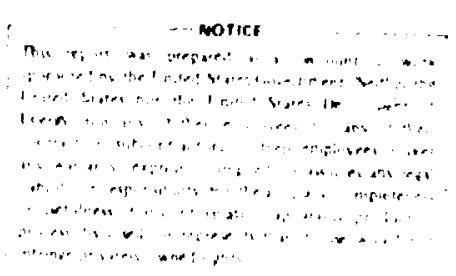

UNTON CARBIDE CORPORATION, NUCLEAR DIVISION

Operating the

Oak Ridge Gaseous Diffusion Plant. - Oak Ridge Nat,ional Laboratory

Oak Ridge Y-12 Plant.

Paducah Gaseous Diffusion Plant.

for the

DEPARTMENT OF FNERGY 
TABLE OF CONTENTS

ABSTRACT .......................... 1

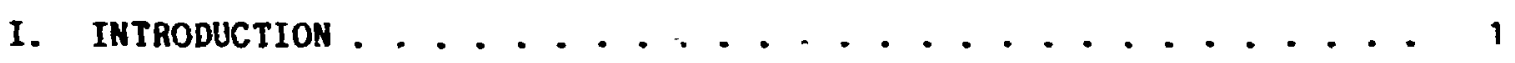

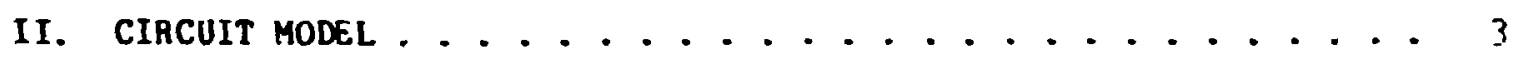

III. POWËR SUPPLY RODRLS . . . . . . . . . . . . 10

IV. FEEUBACK SYSTEM ........................ 11

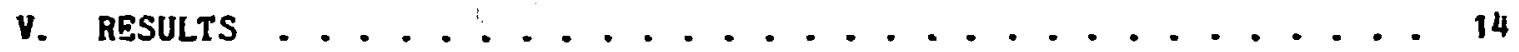

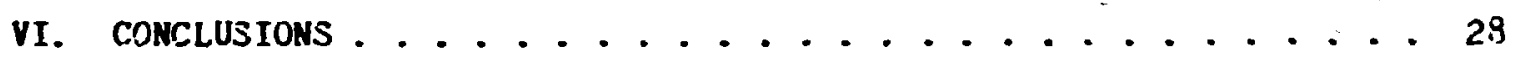

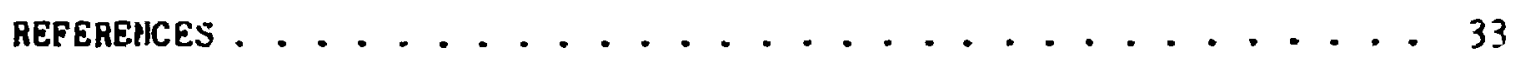

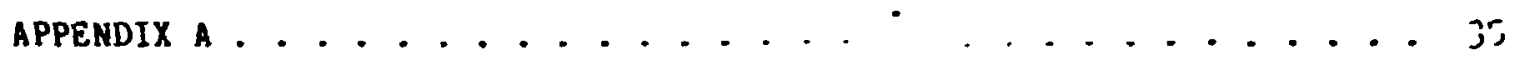


List of Figures

Figure 1. The chosen coil arrangement. Each rectangle represents a single coil. Only the upper half plane is shown. Ho:sever, the coils are symmetric about the $\mathrm{R}$ axis ............... i

Figure 2. The behavior of the voltage and current in the current controlled power supply model. A complete explanation is contained in the text . . . . 12

Figure 3. The horizontal position and current behavior when $\bar{B}$ is raised from .5 to is in 20 msec.

Heating starts at $40 \mathrm{msec} . . . . . . . . .16$

Figure 4. The horizontal position and current behavior when $\bar{B}$ is raised from .5 to $24 \ldots . . . . . .17$

Figure 5. The horizontal position and current behavior

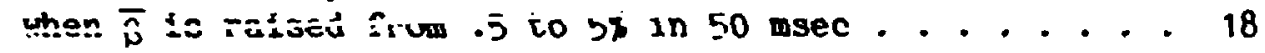

Figure 6. The response of the plasma horizontal position and currents to a demand that the position move in $3 \mathrm{~cm}$. The demar.d is int,iated at $40 \mathrm{msec} . . . .20$

Figure 7. As Figure 6 except the demand was for an outward motior, of $3 \mathrm{sm} . . . . . . . . . .21$

Figure 8. The response of the plasma horizontal position and currents to a demand that $\left|I_{p}\right|$ increase by $10 \mathrm{kamps}$. The demand was initiated at $40 \mathrm{msec} . . .22$

Figure 9. As Figure 8 except the demand was for a decrease of $10 \mathrm{kamps}$................ 23

Figure 10. The growth rate for vertical motion vs elongation for two different values of $\bar{B}$. . . . . . 24

Figure 11. The vertical motion when a demant was made that the plasma move upward $3 \mathrm{~cm}$ in 20 mser........ 26

Figure 12. The current response to a demand that the plasma nove upward $3 \mathrm{~cm}$ in $20 \mathrm{msec}$. . . . . . . . . $? 7$ 
List of Tables

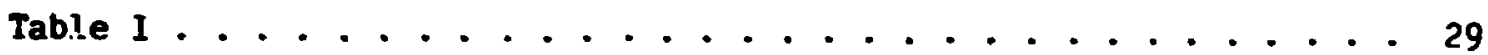
Table II ........................ 29

Tabie III . . . . . . . . . . . . . . . . . . 30

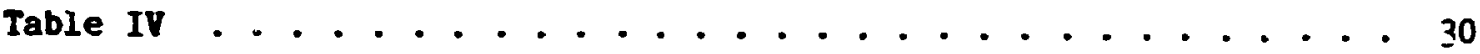

Table V........................... 31 


\section{ACFNONLEGMENTS}

My thanks to the Fusion Energg Division for funding this effort and to Ms. Janice Hughes for her freparation of the manuscript. 
FEEDBACK CONTROL HODELINS OF PLASHA POSITIOH AND CURRENT DURING INTENSE HEATING IH ISX-B

\author{
L. A. Charlton \\ D. U. Swain \\ ธ. H. Neilson
}

\begin{abstract}
ABSTAACT
The ISX-B Toicanak ar ORNL is designed to have 1.84a (and eventually j(w) of neutra? bean power injected to heat the plasaa. This power ay raipe the $\bar{B}$ of the plasina to over 58 in less than - 50 usec if the plasna is MHD stable. The results of a numerical simulation of the feedback control system and poloi coil power supplies necessary to control the resulting noncırcular (D-shaped or elliptical) plasica are presented. The resulting feedback control aystem is shown to be straightforward, al though nonlinear voltage-current. dependence is assumed in the power supplies. The requi.'ed power stipolied to the poloidal coils in order to cont: in the plasma under the high heating rates is estimated.
\end{abstract}

\title{
I. INTRODUCTION
}

The IJX-B Tokamak is designed to study the Iiwits on $\bar{B}$ atta:nable in a Tokamak subjected to large amounts of supplementary heating. Assuming a constant energy confinement time $\tau_{E}$, and noting that $\bar{B}=\mathrm{P}_{\mathrm{OH}} \tau_{E}{ }^{\prime U_{\mathrm{p}}}=.005-.01$ in most onmically heated Tokamaks to date, then attaining $\bar{\beta}=.05-.1$ will require supplerental heating that will provide $P_{\text {SUPP }}=5-10 \times P_{O H}$.

In the case of ISX-B, this heating will be provided by two neutral injectors capatle of providing up to $1.8 \mathrm{MW}$ at $45 \mathrm{keV}$ into the plasma, with the capability of upgrading the injectors to $3 \mathrm{MH}$. This power is in the lange of 5-10 times the chmic heating power observed on ISX-A and expected on IS $X-B$. The resulting sudden changes in llasma pressure caused by such massive heating will require a good feedback control systen to keep both plasma position and current at desired values. In 
this paper, we describe such a sinulation that was carried out for the particular case of ISI-B. Bowever, the method and sone conclusions are sufficiently seneral to warrant a wore general interest.

Shere are two special itens that were considered for ISI-B, and ay be of interest. First, the plasma enlongation and shape can be changed by spesial shaping poloidal coils. This shaping akes the plasa position dymanically unstable in the vertical direction and 30 an active feedback control system nust be used to maintain plasia vertical position. The interaction of this systen with the horizontal control system during shaping and/or heating stindied to determine if any instabilities would develop due to cross-coupling. None were found in our system.

Second, the ISX-B device is designed to use a coupled control system, where plasma position and eurrent are both strongly affected by current in each of two poloidal coil sets (the "Inner" and "outer" windings). That is, the standard ohic heating and vertical field windings conventionally used in Tokamaks have been replaced by two windings with non-orthogonal control functions. This procedure simplified the coll design for ISX-B, and the feedback simulation Indicater that the coupled system works effectively at position and current control.

Sections II, III, and IV describe the circuit model, power supply models and feedback system. Results and conclusions of the simulations are presented in section $V$. 


\section{CIRCUIT MODEL}

A Tokanaix device as a whole is predoninantiy an electrical system consisting of power supplies, coll sets, eddy currents, etc. It thus seens reasonable to wodel the behavior of such a system by treating the various components as electrical eircuits. Probably the reakest point in our circuit podel is the assuption that the plaswa is a current filament. A real flasma, of course, has a finite extent. Each part or the plaswa interacts with the rest of the systen in a different, way. However, for wany purposes, the average behavior of the plaswa should be well approximated by a filamentary current located at the mean position of the plasma current, defined by

$$
B_{I}=\int_{A} j(R, z) R d R d z / \int_{A} J(R, z) d R d z
$$

The ISX-B device is a Tokamak with a major radius of $93 \mathrm{~cm}$. The vacuua vessel is rectangular with colls mounted around the outside. These coils may be connected in various ways to achieve maximum plasma contrcl. The particular arrangement used in this study is shown in Fig. 1. The inner (I) and outer (O) coll set currents were used to control the plasma horizontal position and plasma current. Vertical position was maintained by the radial field (RF) coil set current. Plasma shape could be changed by varying the current in the set labeled S.

The ISX-B vacuum vessel has a liner with a thick wall in which eddy currents can flow. It is split into two halves with insulators, so no net current can flow tisidaliy in the vacuum vessel. Higher mudes, however, can occur, and hase a significant effect on the plasma 


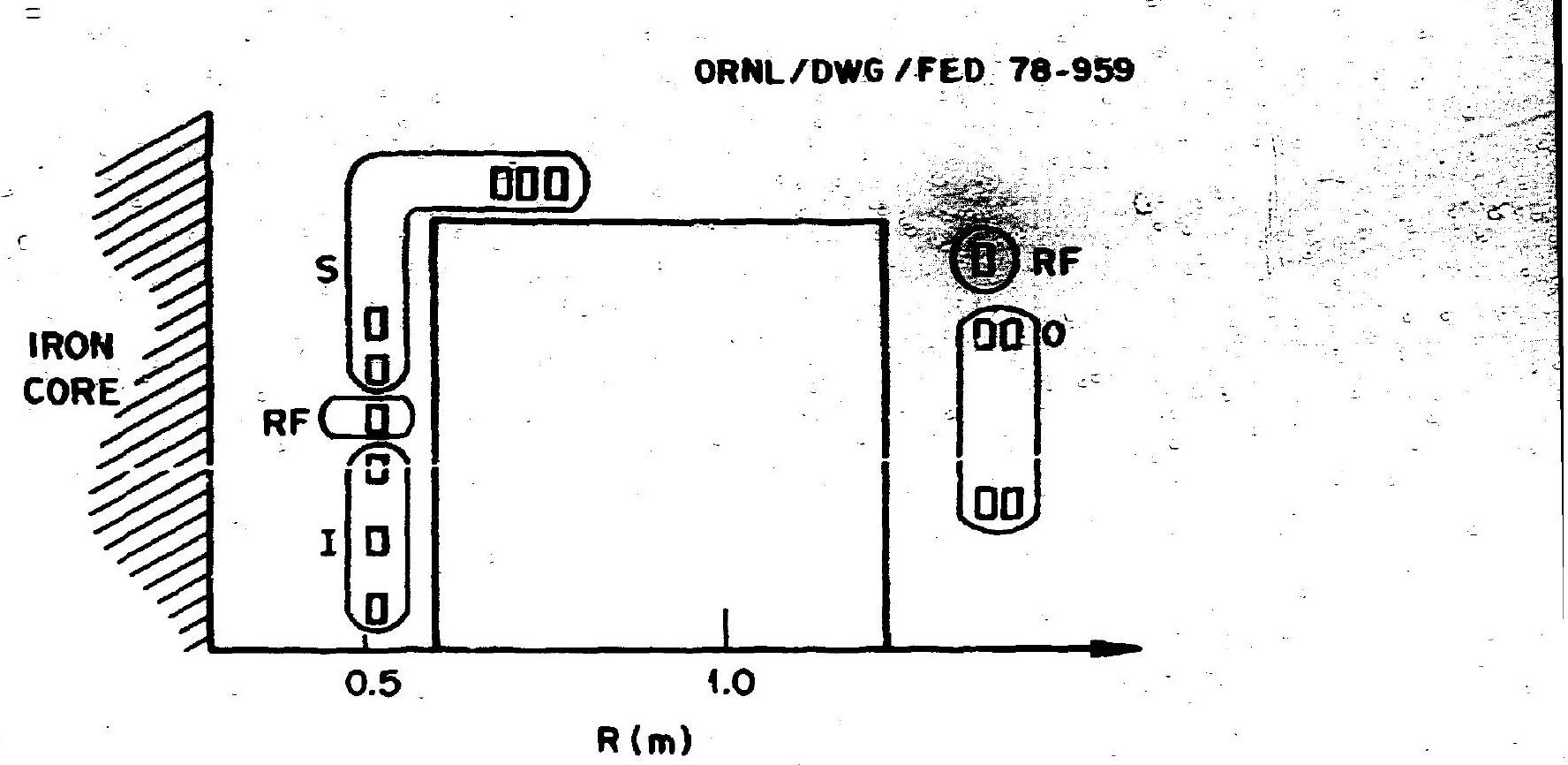

Figure 1. The chosen coil arrangement. Each rectangle represents a single coll. Only the upper half plane is shown. However, the colls are symetric absut the $R$ axis. 
control. He have included the two wost significant in this sivulation, which we cail the first symetric (in Z) and first antisymetric modes. They have decay times of 5-6 $\mathrm{msec}$, and influence the plasa horfeontal and vertical position control, respectively.

The plasua motion was defined by assuning the plaswa noves through a series of equilibrium states. These states were described by the furmalis of Ref. 1 where the horizontal position of the plassa is given by

$$
R=-\frac{I_{1}}{k_{i} B_{i}}\left(2.1+B_{p}\right)
$$

with poloidal beta $\left(\beta_{p}\right)$ given by

$$
\begin{aligned}
& \beta_{p}=\frac{k_{2} \overline{8}}{J_{1}^{2}}, \\
& k_{1}=\left(4 \pi \mu_{0}: \sqrt{\left(1+\varepsilon^{2}\right) / 2},\right. \\
& k_{2}=\left(a_{0} R_{0} / a\right)^{2} 2 I_{1}^{2} /\left(1+\varepsilon^{2}\right),
\end{aligned}
$$

I refers to the plasma current, $q_{0}$ is the safety factor, a is the etiective pissa radius, $\varepsilon$ the elongation, $\bar{B}$ the total average beta, and $P_{1}^{P}\left(R_{0}\right)$ the initial current (positisn). In Eq. II-l, $B_{v}$ is the vertical magnetic fleld of the plasma "filament" iocation, given by

$$
B_{v}=\sum_{i} I_{i} f_{i}(R, z)
$$


where the sum runs over all the current carrying components and the $f_{i}$ give the magnetic field per unit curren: tue to each component. Tre inclusion of the elongation in tne above is dise io $\mathrm{N}$. Uckan [2]. The vertical plasma position was defined by requiring that the radial magoetic field $B_{r}$ at the plasms location be zero di each instant; $1 . e$. ,

$$
B_{r}=\sum_{1} I_{1} g_{1}(R, z)=0
$$

Equaticns II -5 and II-6 assume the magrietic field depends lin6arly on each current. For the results to be presented later, the $f_{i}$ and $f_{i}$ wers calculater. by Tucker and Peng [3] using a two Jimensional code that included the effects of the iron rore used in ISX-B.

Equations II-1 through II-6 define a plasma equilibrium in a necessarily simple way. The validity of these equations was tested hy comparing the curients required for equilibrium to those required when the full Graj-Stafranov equation is solved. The currents at all values of $B$ were the same within $108[H]$; for the low-B cases agreement, was much better.

The srent filament model for the plasma was also tested by comparing the currents required for equilibrium asing a filament to those neejed when tr.a current density was a Gaussi:n and the magnelic field was given by

$$
B_{r}(R, z) \propto \sum_{1} \int_{S^{\prime}} J\left(R^{\prime}, z^{\prime}\right) B_{1}\left(R^{\prime}, z^{\prime}\right) I_{1}
$$

where $S^{\prime}$ is the plasma two dimensional surface. The currents were the same within 19 [5]. The above tests aren't claimed to be conclusive. They do, however, tend to justify the model. 
With the above, nine equations are defined. They are (see Table I for definition of the subscripts)

$$
\begin{aligned}
& \sum_{j} L_{1 j} \dot{I}_{j}+\frac{i}{j} I_{j} i_{1 j}+B_{1} I_{1}=0, \\
& \sum_{j} L_{i j} \dot{I}_{j}+I_{1} \dot{L}_{i j}+R_{i} I_{i}=V_{i}, \quad(I=2, \ldots 7) \\
& \dot{R}=A+\sum_{i=1}^{i} n_{i} \dot{I}_{i}+D \dot{Z},
\end{aligned}
$$

and

$$
\dot{z}=\sum_{i=1}^{7} k_{i} \dot{I}_{i}+E \dot{R}
$$

where the dot cver a quantity denotes time derivative, the $R_{1}$ are circiit resistances, the $L_{i j}$ are inductances and the $v_{i}$ are voltages. In the resuits presented later, the plasma resistance $\left(R_{1}\right)$ is taken to be zero and $v_{1}=V_{6}=V_{7}=0$. Equations II -10 and $I I-1$; result from taki,!g time derivatives of Eqs. II-1 and II-6. Thus the coefficients in II-10 and II-11 are defined and given in Appendix $A$. Only the $\dot{L}_{1 j}$ enter since all conponents are stationary exsept the plasma. These are found from

$$
\dot{L}_{1 j}=\frac{\partial L_{1 j}}{\partial R} \dot{R}+\frac{\partial L_{1 j}}{\partial z} \dot{i} .
$$

These nine equations can be written in the form

$$
\underline{L} \dot{I}+\underline{R}=\underline{v}
$$

where the boldface denotes a matrix, 


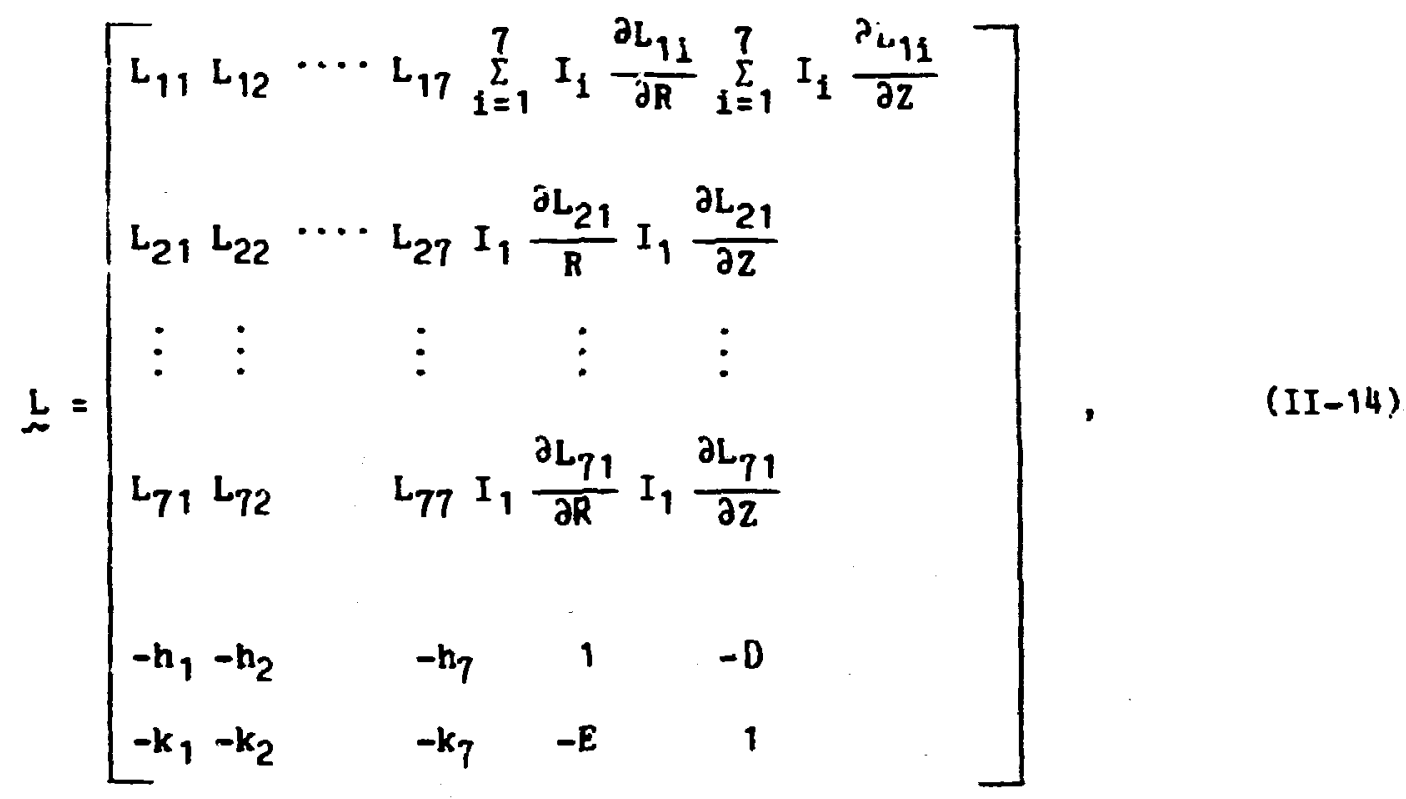

$\dot{I}=\left[\begin{array}{l}\dot{I}_{1} \\ \dot{I}_{2} \\ \vdots \\ \dot{I}_{7} \\ \dot{R} \\ \dot{z}\end{array}\right]$,

(II-15)

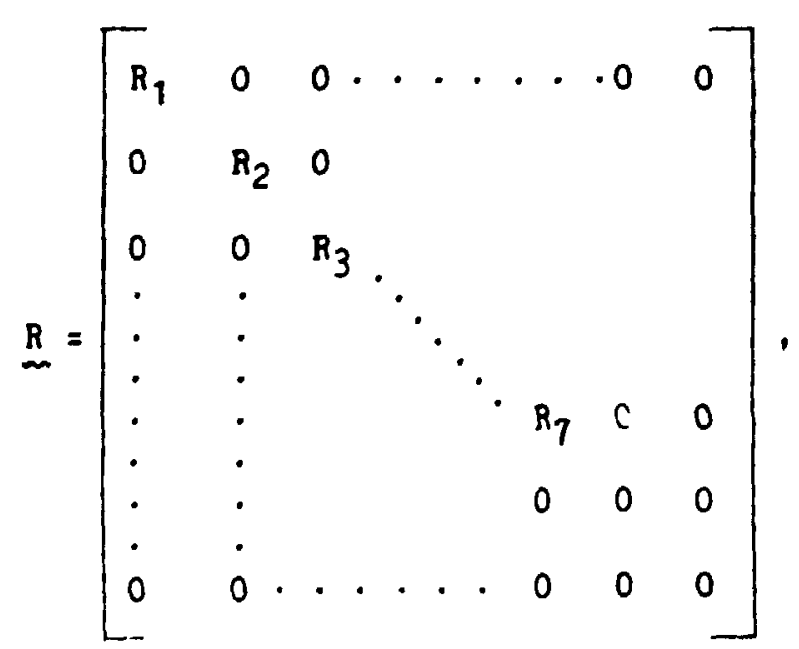


$v=\left[\begin{array}{l}0 \\ v_{2} \\ v_{3} \\ v_{4} \\ v_{5} \\ 0 \\ 0 \\ A \\ 0\end{array}\right]$,

The manner in which the voltages $\left(V_{i}^{\prime} s\right)$ were found will be discussed in the next section. Equation II-13 can be solved for the time derivatives to yield

$$
\dot{I}=L^{-1} V-L^{-1} R I
$$

This is the form required for standard computer codes which solve differential equations. For the work here, $\operatorname{ODF}[61$ was used.

The radial position of the plasma ( $R$ in Eq. II-10) must be interpreted as the average radial position of the plasma current density. This, in general, is not the iocation of the geometrical center of the plasma since the peak in the current density tends to move outward relat,ive to the geometrical center as $\bar{B}$ increases [7]. Thus a method is needed for converting the $R$ in the preceding equations to a plasma position. The method used here was to parameterize results taken from Ref. 7 by the expression 


$$
\frac{R-R_{p}}{a}=.05+.95 \frac{e^{q}}{e^{q}+e^{-q}}
$$

where

$$
q=(B \quad 5.8) / 2.5 \text {, }
$$

$\bar{B}$ is expressed in percent, a is the plasma radius and $R_{p}$ is the plasma position.

III. POWER SUPPLY MODELS

In the medel various parameters can be conirolled by changing the voltages (the $v_{1}$ of Sec. II) across the power supplies. If the physical power supply is directly voltage controlled: then a reasonable mathematinal model is

$$
\tau_{1} \dot{v}_{1}=e_{1}
$$

where $\tau_{i}$ is the appropriate time constant and $e_{i}$ is the error signal. The error signal, at some time, is the desired amount the voltage should change; this change arriving about $\tau_{1}$ later. The soecific form for $e_{i}$ will be discussed in the next section. This model was used for the shaping coll power supply.

The rest of the power supplies are current controlled and thus a more complicated model is needed. The one used here utilizes a control signal ( $I_{1}^{c}$ ) which satisfies 


$$
\tau_{i} i_{i}^{c}=e_{i}
$$

where $\tau_{i}$ and $e_{i}$ are as above. The voltages are ti.en determined by the "logic diagram" shown in Fig. 2a. The various parameters are chosen to as closely watch the model to the behavior of the physical power supply as possible. The model is shown graphically in Fig. $2 b$. Plotted is the voltage $\left(V_{i}\right)$ as a function of the current $\left(I_{i}\right)$. The power supplies for the inner and outer coils were modeled in this way with parameters as shown in Table II.

The radial field power supply was described by a model which is a somewhat simplified version of libs: just described. Namely,

$$
V_{5}=R_{e f f}\left(I_{5}^{C}-I_{5}\right)
$$

with $R_{\text {eff }}=30 \mathrm{~m} \Omega$. If $\left|V_{5}\right|>36 \mathrm{~V}$., the voltage was clamped at $\pm 36 \mathrm{~V}$.

\section{FEEDBACK SYSTEM}

The results of the previous sections were used to design the feedback syrism for ISג-B. "Design" means simply finding the best form for $e_{1}$ in Eqs. III-1 and III-2. The pi imary requirement was that the plasma position be maintained (i.e., $R$ and $Z$ resulting fron the solutions to Eqs. II-10 and II-11 be the desired values).

For a change in $\bar{B}$ from $.5 \%$ to 29 in $20 \mathrm{msec}$, it was found that using error signals profortional to the deviation of the position plus the deviation of the velocity from ine desired values worked quite well. However, the nlasma current varled by large amounts. It was 
ORNL / OWGIFED 78-960

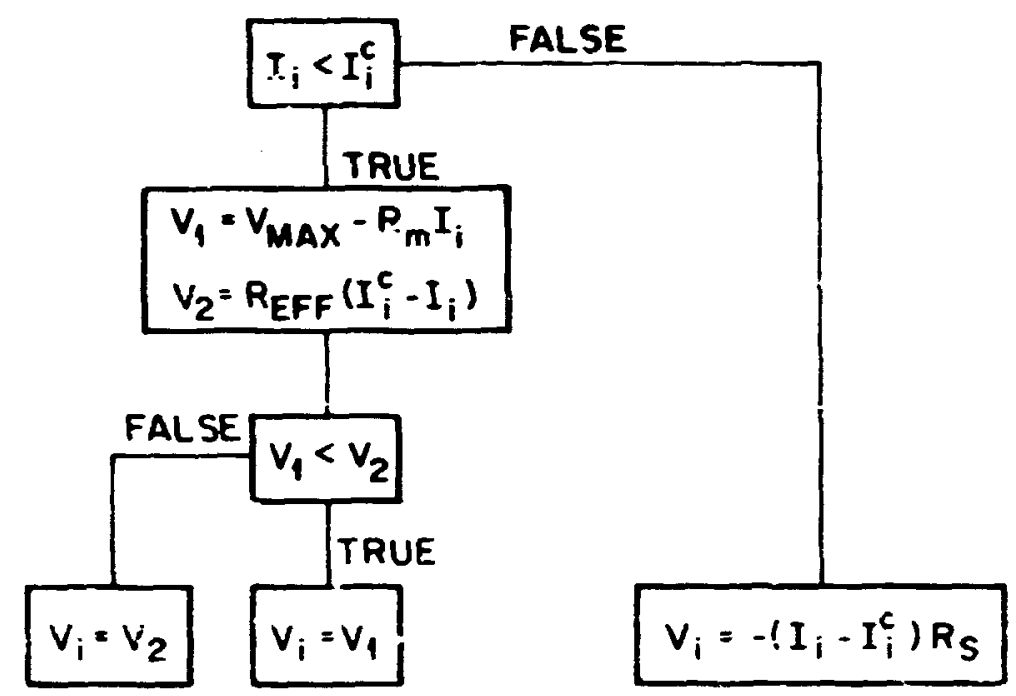

(a)

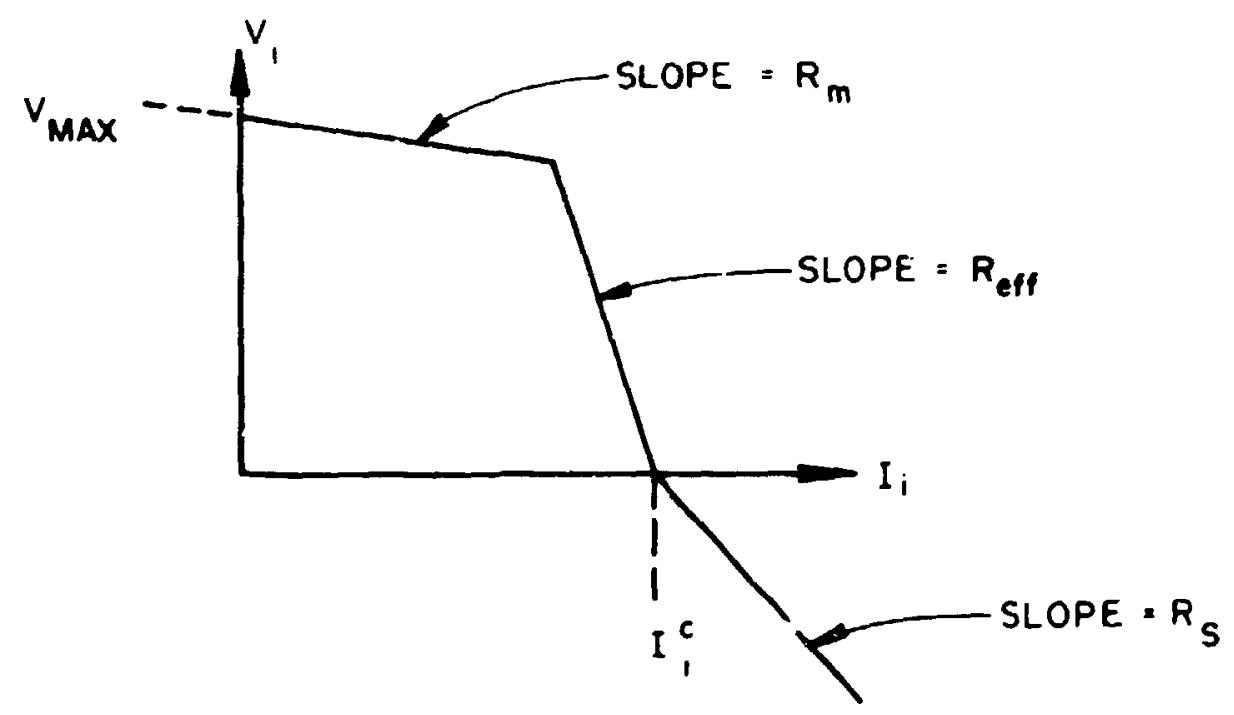

(b)

Figure 2. The behavior of the voltage and current in the current controlied power supply model. A complete explanation is containes in the text. 
thus necessary to feed bacik on tho olasua current and its first time aerivative also. In particular, the following forms were used:

$$
\begin{aligned}
& e_{2}=k_{I}^{I_{p}}\left[\Delta I_{p}+\tau_{I}^{I_{p}} \Delta \dot{I}_{p}\right] \\
& e_{3}=k_{0}^{R}\left[\Delta R+\tau_{0}^{P} \Delta \dot{R}\right] \\
& e_{4}=k_{s}^{I_{s}}\left[\Delta I_{s}+\tau_{s}^{I_{s}} \Delta \dot{I}_{s}\right] \\
& e_{5}=k_{R F}^{Z}\left[\Delta z+\tau_{Q F}^{Z} \Delta \dot{Z}\right] .
\end{aligned}
$$

The suiscripts on the defined in table I. Mre descriptive labels have been used on the right-hand side of the equations. The $k$ 's allow the strength of the signal to be varied, the $\tau$ 's weighi the relative importance of the two terms, and

$$
\Delta Q=Q-Q_{0}
$$

$Q$ in the above is any of the quantities appearing in Eqs. IV-1 through IV -4 which are preceded by $\Delta$ and $Q_{0}$ is the desired value. Ir: all cases, tile $\tau$ were chosen to be 5 msec. Making $\tau$ larger tends to improve the response of the system. However, taking a derivative of an analog signal ( $I_{p}$ or $R_{p}$ ) introduces some noise into the signal, which can cause trouble in the crerall feedback loop. A value of 5 msec for $\tau$ was chosen as a reasciable compromise between these conflicting goals. All parameters in Eqs. IV-1 and IV -4 are given in Table III. These parameters were used to obtain tre results in the next section. 
As reflected in the equations above, the inner ccils were usec to control the plasma current, the outer to control the plasaa radial position, and the radial field coils were used to control the vertical positior. The error signal for the shaping coils (Eq. IV-3) was used both to give the plesma the desired shape and to maintain that shape.

The above represents an orthogonal feedback systes in that only one quantity is controlled with each coil set. Hon-orthogonal systems were used but none were found which gave appreciably better control.

The orthogonal system aiso has an advantage in that no locking of the system can occur. This problem occurred when the inner and outer coils were each used to control both the radial position and the plasma current. For certain situations (raising $B$ from .5 to 28 in 29 - 3 sec, for instance), the inner pover supply would clamp at zero and the error signal for the outer would be zero due to the radial position demand being equal and opposite to the plasma current demand. Although neither the radial prsitiun nor the plassa current had the desired value, the system was receiving a null error signal. It is thus claimed (if all other things are equal) that an orthogonal system should be used. The above together with Stctions II and III define what was used for the results to be presented in the next section.

\section{RESULTS}

Studies were done which simulated plasma heating (changes in $\bar{\beta}$ ), moving the plasma position, changing the plasma clirrent, and shaping the plasma. The cuntrol achieved for the first three cases is shown in Table IV. In the table $\Delta R_{m x}\left(\Delta I_{m x}\right)$ gives the maximum deviation of the horizontal position (plasma currert) from the desired value. I? these 
cases the vertical deviation was zero. Control better than that shown ir. the table could be achieved if extremely large error signal coefficients (the $k^{\prime} s$ in Eqs. IV-1 to IV-4) were used. For instance, changing $k_{0}^{R}$ to $24000 \mathrm{kamps} / \mathrm{m}$ redueed $\Delta R_{\operatorname{mx}}$ to less than $1 \mathrm{~cm}$. for the heating simulation which changed $\bar{\beta}$ from .5 to $2 \%$. The electronics in the actual ISX-B device, however, probably couid not handle such large error signal coefficients. Thus, the more rististic vilues given in Table III were used for these results.

For the $\bar{\beta}$ excursions the control is shown in Figs. 3,4 , and 5. The plasma position curves show both the plasme location and that of the model current element (the relation between the two is given by Eq. II-19). All currents excep; those in the radial field and shaping coils are st.own. Control for the $\bar{B}=18$ excursion is unremarkabie and is shown only for comparison. The $\bar{\beta}=2 \%$ case shows an overshoot in position. That is, the plasma position moves past the desired location. It is, however, back at its injtial position about $10 \mathrm{msec}$ after the keating is completed. For $\bar{B}=5 \%$, there is also an overshoot, but again the desired position is achieved about 10 msec after the heating is stopped.

As stated previously, the main purpose of the work presented in this paper was to develop and test a control systers which would maintain the desired plasma parameters (position and current) during intense heating. However, a further test of the conc.ol system is to demand that the plasma position or current change by some specified amount and find the reaction of the system. For effective control it is also necessary that the parameter that is held constant must remain so. 

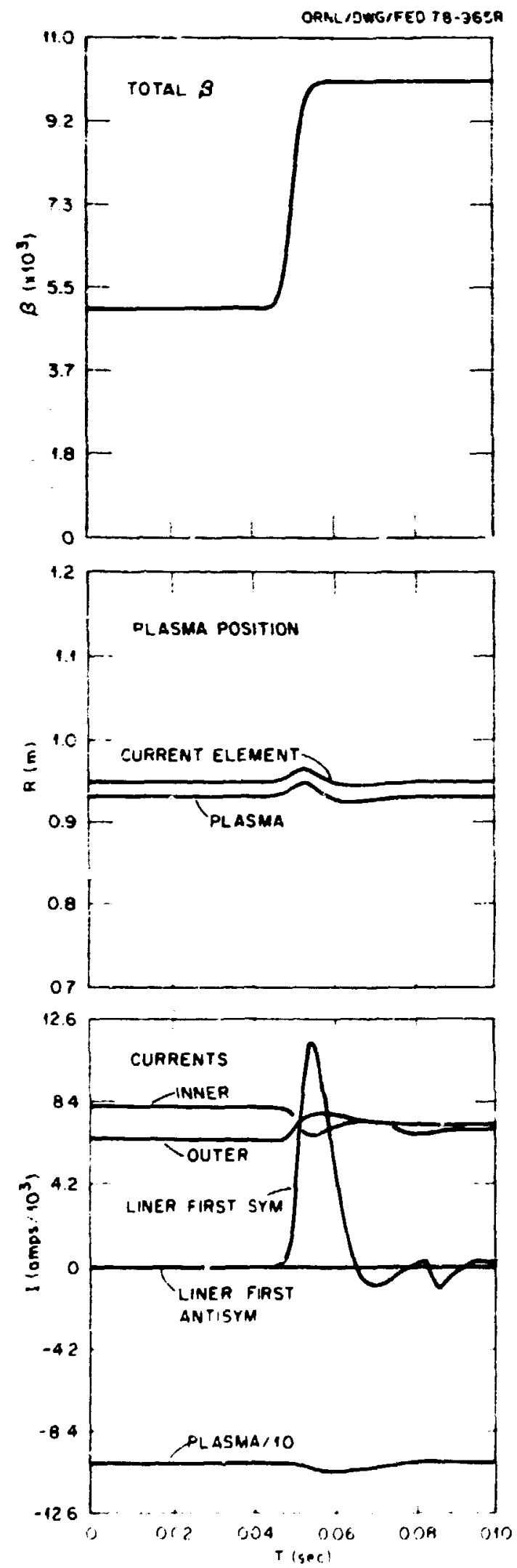

Figure 3. The horizontal position and current behavior when $\bar{B}$ is raised from .5 to 18 in $20 \mathrm{msec}$. Heating starts at 40 msec. 

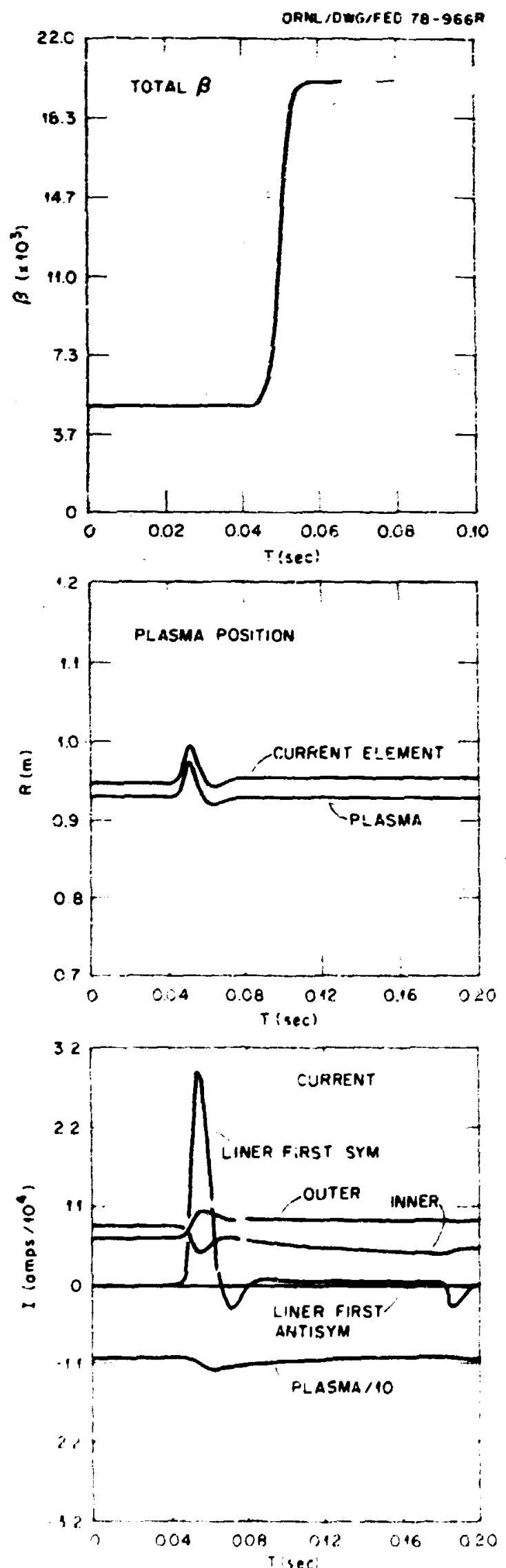

Figure 4. The horizontal position and current behavior when $B$ is raised from .5 to $2 \%$. 

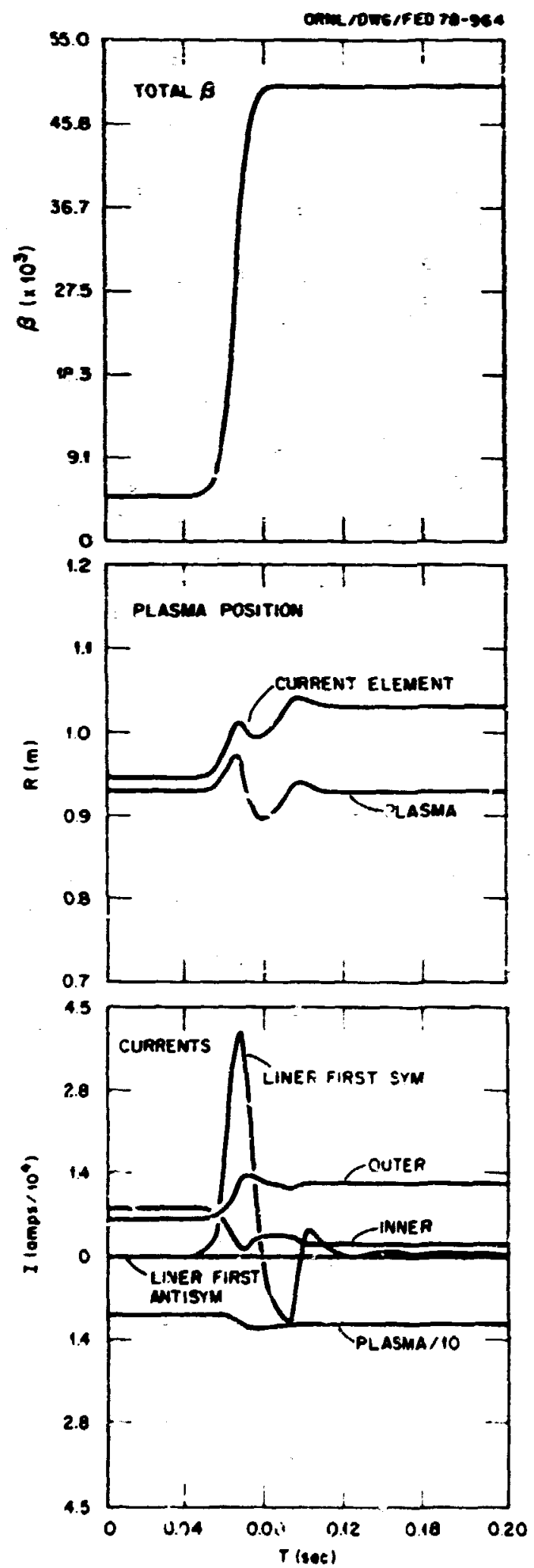

Pigure 5. The horizontal position and current behwior when $B$ is raised from .5 to $5 \%$ in 50 msec. 
Figure 6 strous the results when a $3 \mathrm{~cm}$. inwa:d motion was demanded by changing $R_{0}$ (see Eqs. IV-2 and IV-5) from $93 \mathrm{~cm}$. to 90 cm. at 40 msec. As may be seen, the moticn is concleted in about 10 msec. The plasma current raries during the position change by a negligible amoun:. Figure 7 shows the position response when the piasma is requested to move out 3 ca. Again, this motion is accomplished in about 10 msec with the plasma current kept very nearly constant. Thus, the control system used here can move the plasma by appreciable amounts while holding the plasma current constant to tatter than $1 \%$.

Figures 8 and 9 show the system response to step function demands that $\left|I_{p}\right|$ be changed by $\pm 10 \mathrm{kA}$, from an initial current of $160 \mathrm{kA}$. The response in both cases is to reach the desired current value in approximately $10 \mathrm{~ms}$, with no significart change in plasma position.

In Figs. 6 and 7 the dominant fictor causing the $10 \mathrm{msec}$ response was the 5 msec skin time of the first symmetric liner mode. As can be seen from the figures, substantial clirrent was driven in this mode when the plasma was shifted.

Shaping of the plasma was simulated by requiring that the same amount of current flow in the shaping coils as was required to produce a given elongation in the equilibrius calculation of Strickler and Peng [8! The reguired current.3 are given : 0 Table $V$ for two different values of $\bar{B}$. The vertical inetability was studied by initiating a commard that the plasma more upward $3 \mathrm{~cm}$. in $20 \mathrm{msec}$ and then shuttizs the verical feetbask system off after $5 \mathrm{msec}$ (i.e., setting $k_{R F}^{Z}$ in Eq. IV 4 equal to zero). An exponential of the form $e^{\text {it }}$ was then fitted to the resulting motion giving a growth rate $\%$. Figure 10 shows the 

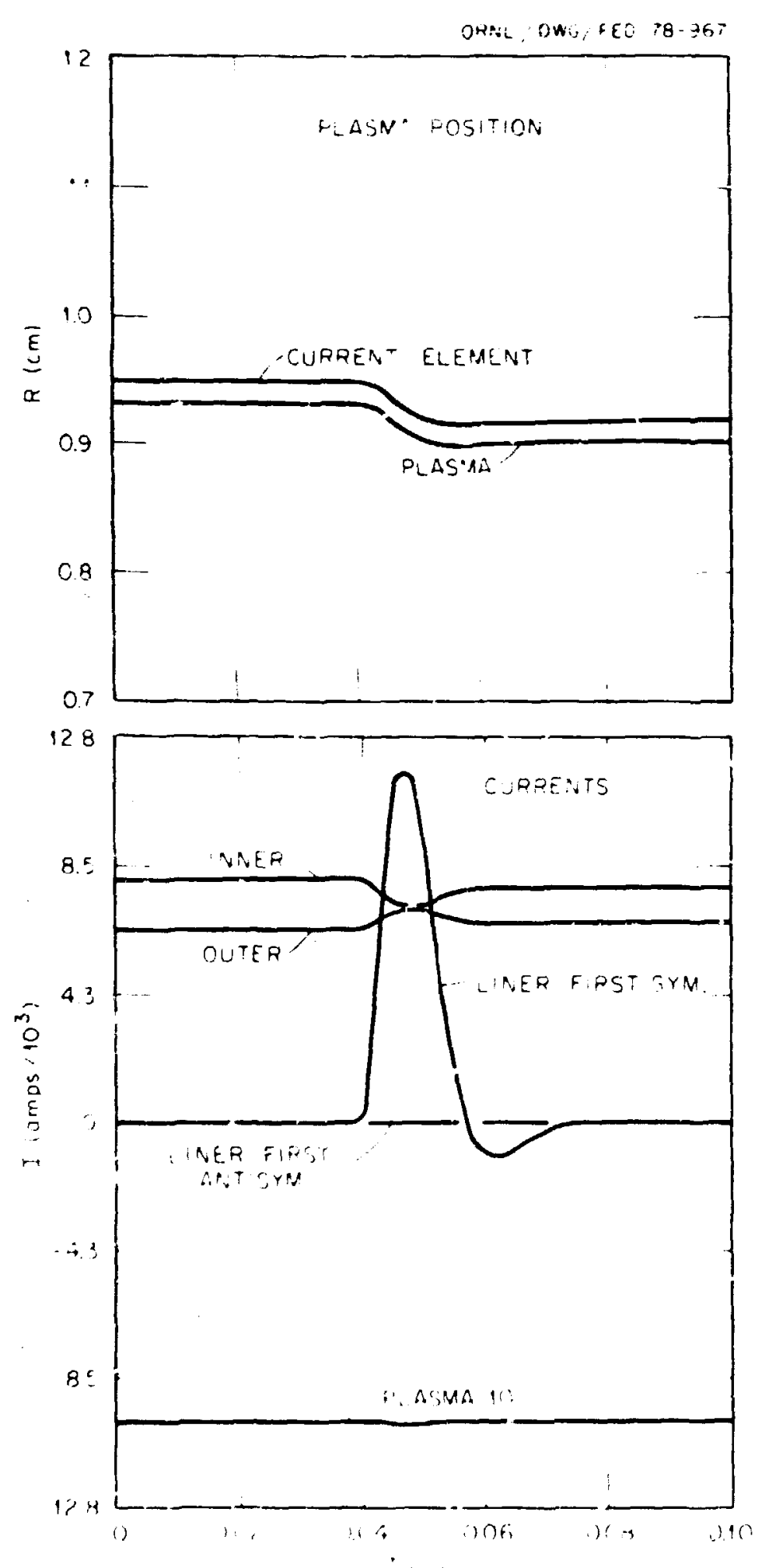

Figure 6. The response of the plasma horizontal position and cuirents to a demand that the position move in $3 \mathrm{~cm}$. The demand is initiated at $40 \mathrm{msec}$. 

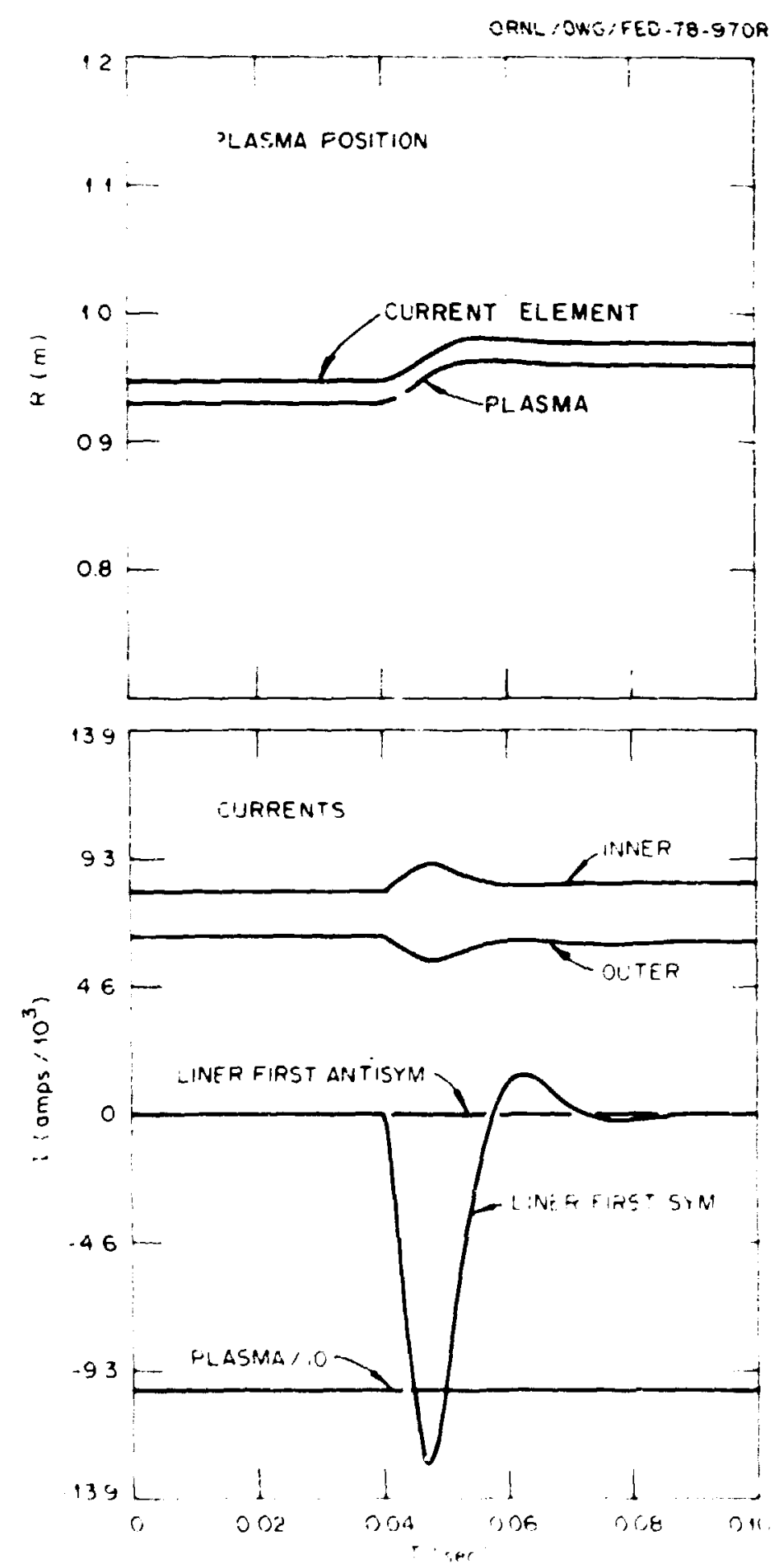

Figure 7. As Figure 6 except the demand was for an ouc vard motion of $3 \mathrm{~cm}$. 


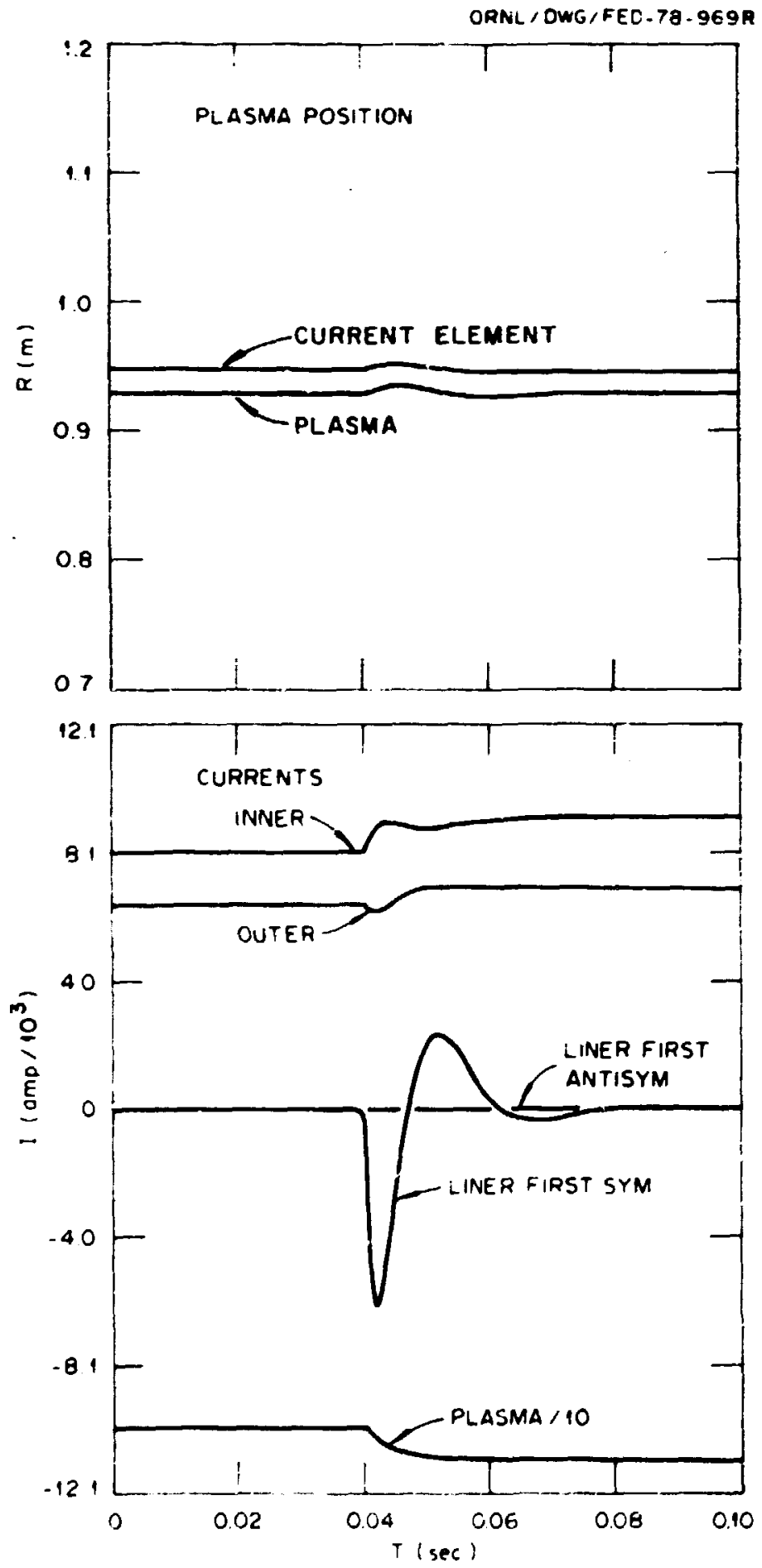

Figure 8. The response of the plasma horizontal position and currents to a demand that $\left|I_{p}\right|$ increase by 10 kamps. The demand was initiated at $40 \mathrm{msec}$ 

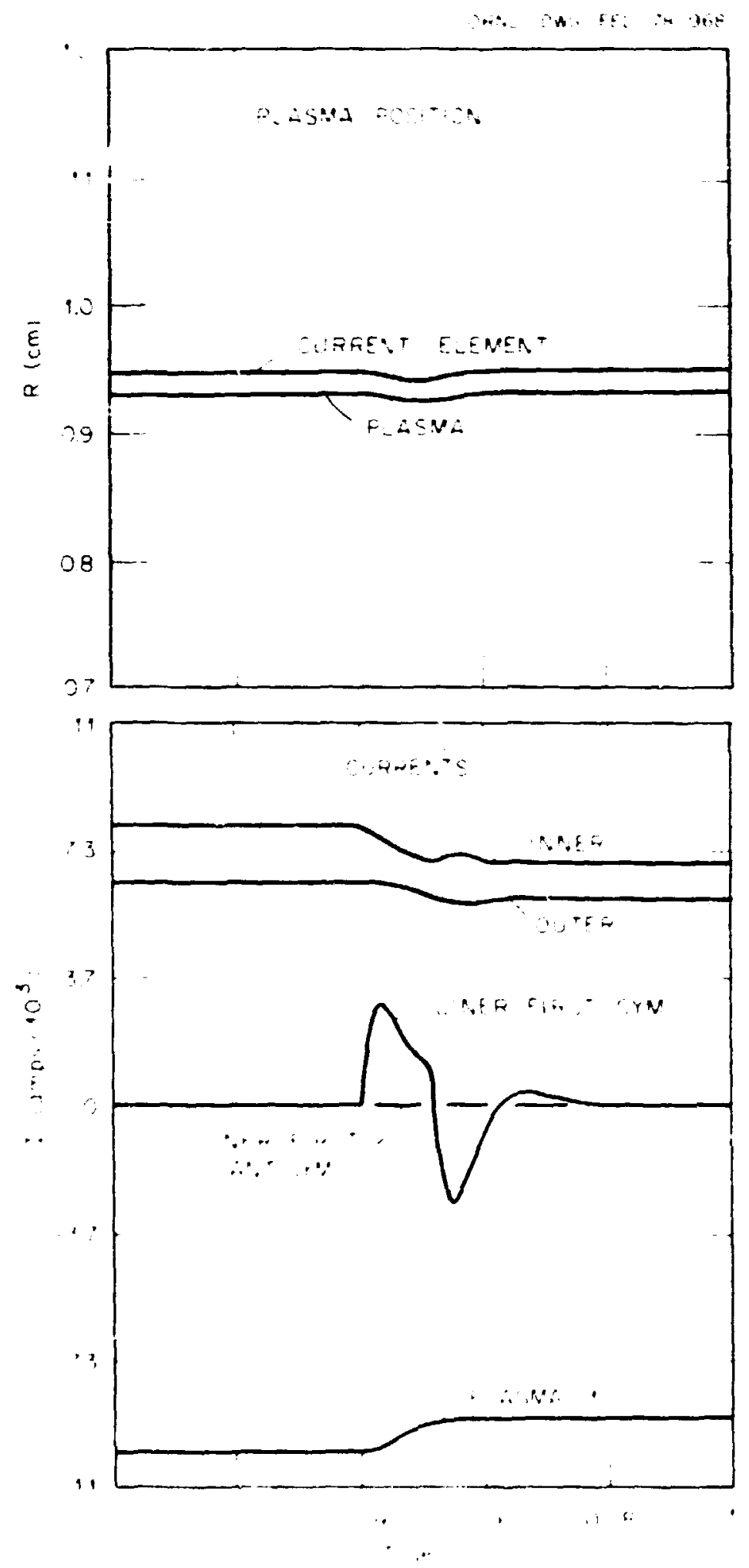

Figure 9. As Figure 8 except the demand was for a decrease of 10 kamps. 


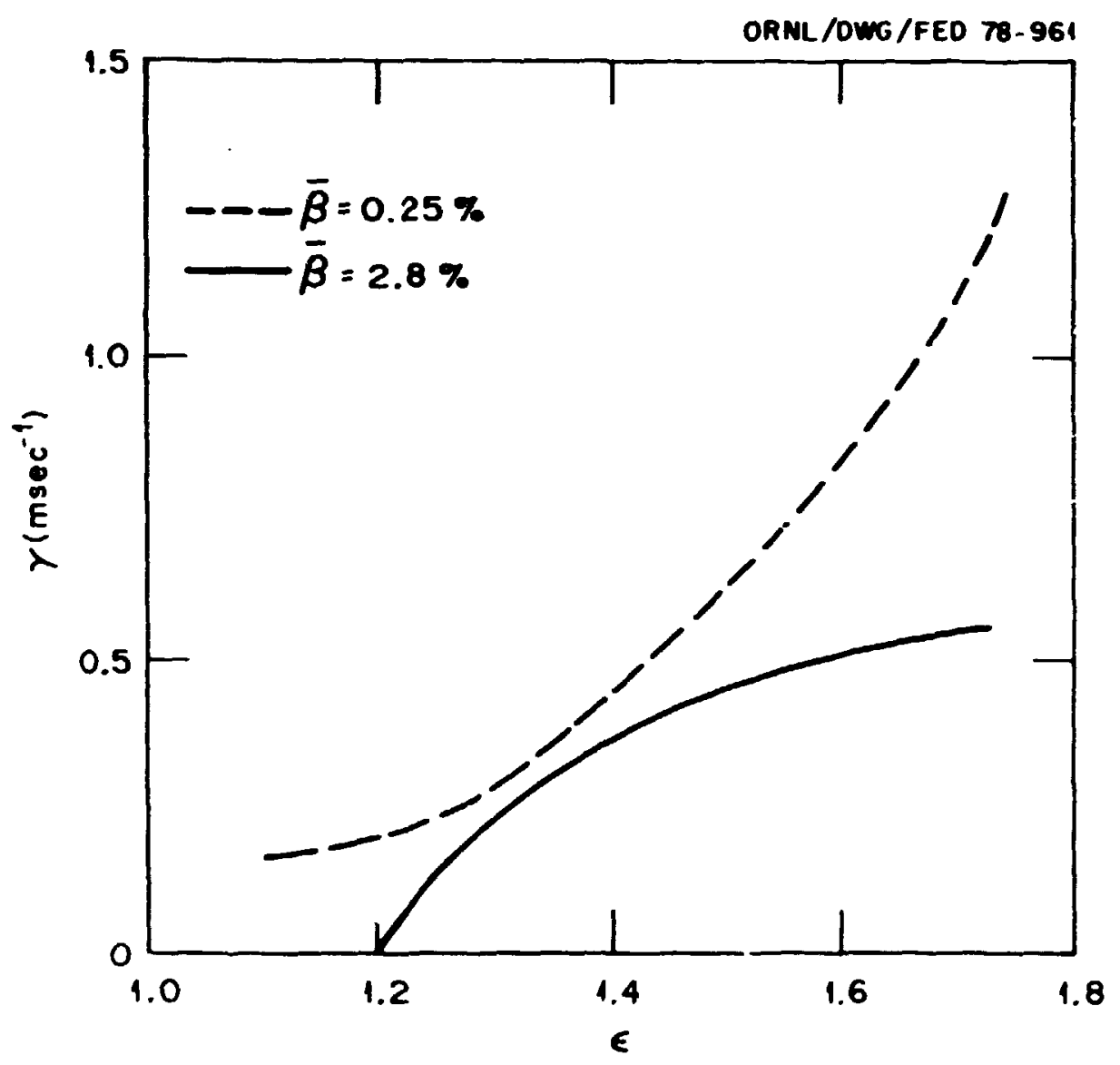

Figure 10. The growth rate for vertical motion vs elongation for two different values of $\bar{B}$. 
growth rate as a function of the elongation for the two values of 3 . The plasma is more unstable at small than large and more unstable the larger the elongation. The $F$ dependence of the growtin rate is due to equilibrium requirements. The smaller $E$ is, the larger the amount of current required in the inner coil set relative to the current in the outer coil set. Both the inner and outer coll sets are destabilizing (that is the radial ield they produce tends to drive the plasma away frow the widplane) but the inner coils are more destabilizing than the outer. Thus the more current that flows in the inner coils relative to tile outer coils, the sore unstable the plasma is. The dependence of the growth rate on the elongation is due to the destabilizing radial field from the shaping coils. The larger the current in the shaping coils, the larger the destabilizing radial field.

The plasma is stable for $\bar{B}=2.8 \%$ and an elongation $<1.2$. The reievant question is, however: "Can the feedback system control the largest instability?" If the feedback system is left on when the " +3 cm In 20 msec" command is given, will the plasma nove the desired distance? Figure 11 shows the response of the system when the above command is given with $\bar{C}=.25 \%$ and $\varepsilon=1.74$. As may be seen, the plasma executes the command. Thus the largest instability in the vertical study is controlled. Figure 12 shows the currents during the response shown in Figure 11. From $t=10$ to $30 \mathrm{msec}$, the plasma is "shaped" by turning up the current in the shaping coils to the required value of -1.1 kamps. At $t=40 \mathrm{msec}$, the plasma is told to move up 3 $\mathrm{cm}$. This motion is produced by the current seen in the radial field coils. During the above commands, the radial position is maintained to within $2 \mathrm{~mm}$ and the plastia current is constant to witi... 15 amps. 
26

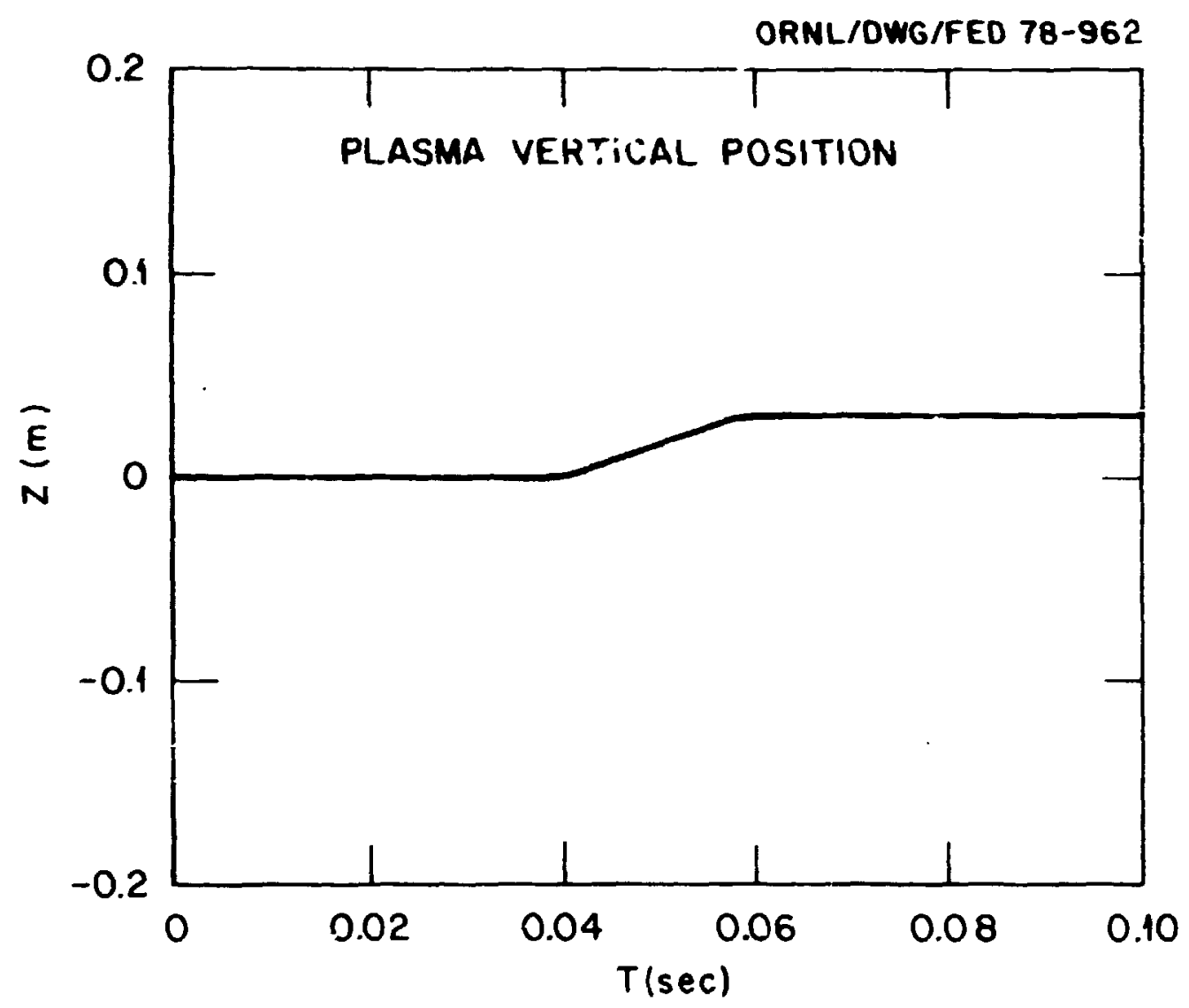

Figure 11. The vertical motion when a demand was made that the plasma move upward $3 \mathrm{~cm}$ in 20 user. 


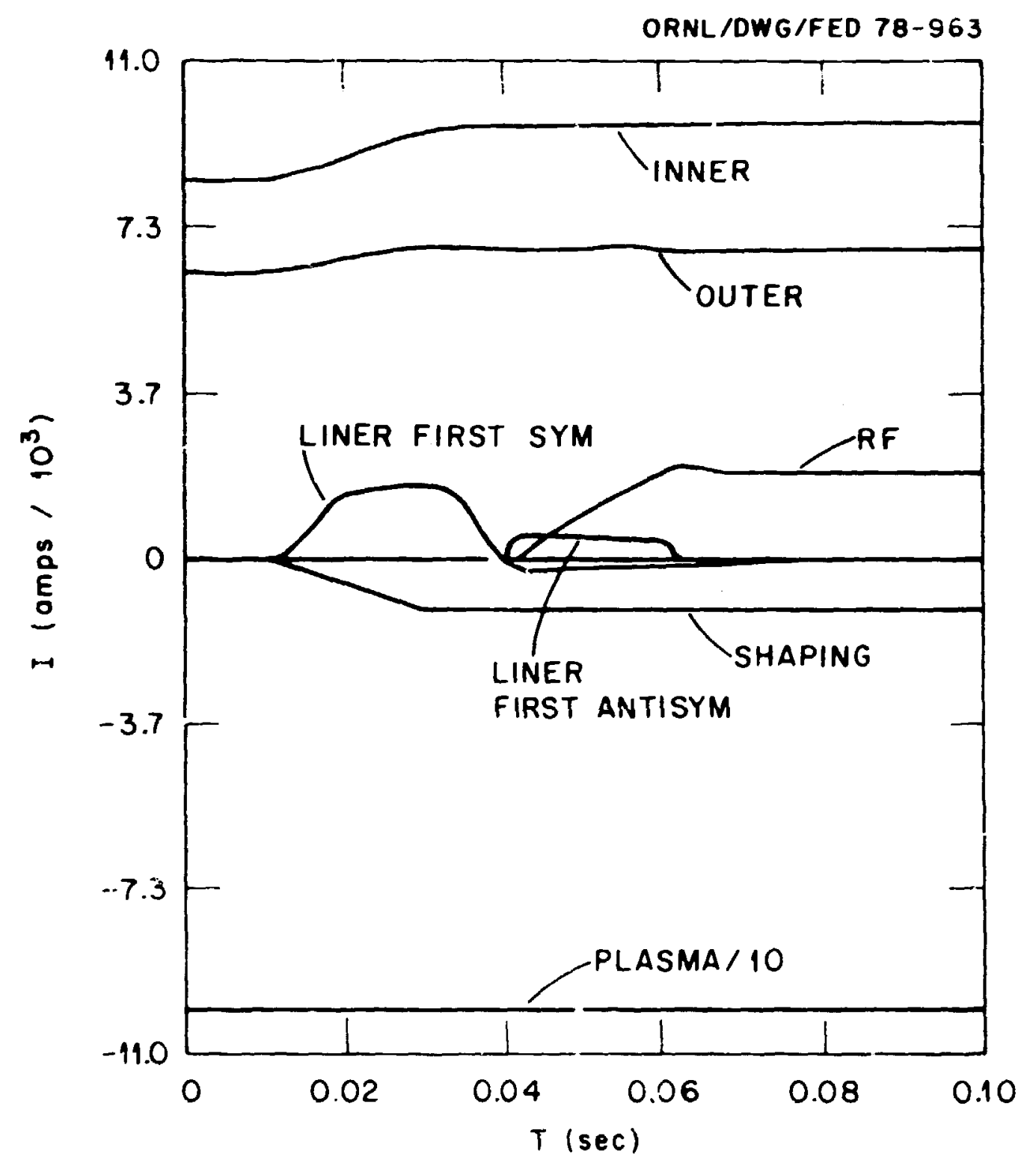

$\because$ gure 12 . The current response to a demand that the plasma move upward $3 \mathrm{~cm}$ in $20 \mathrm{msec}$. 
These almost constant values are due to tie change in the currents in the inner and outer soils produced by the feedback system.

\section{vI. CONCLUSIONS}

The ISX-D device with the coil arrancement shown in Fig. 1 can control the plasma for a variety of paramiter charges with a feedback sjstem which acts only on the plasma current and position and on the first time derivative of these quantities. The mvariety of parameter changes" include 1) $\bar{B}$ changes at a .075\%/msec rate, 2) position changes of $3 \mathrm{~cm}$, and 3) plasma currer.t changes of 10 kamps. A more general conclusion is that axisymetric modes can be controlled with a reasorably simple feedback system. 
TABLE I

\begin{tabular}{cl} 
Label & \multicolumn{1}{c}{ System Component } \\
1 & Plasma \\
2 & Inner Coils (I) \\
3 & Outer Coils (O) \\
4 & Shaping Coils (S) \\
5 & Radial Field Coils (RF) \\
6 & Liner 1st Antisymmetric Mcde \\
7 & Liner 1st Symmetric Mode
\end{tabular}

TABLE II

\begin{tabular}{lll} 
& \multicolumn{1}{c}{ Inner } & Quter \\
$V_{\text {max }}$ & $72 \mathrm{~V}$ & $130 \mathrm{~V}$ \\
$R_{\mathrm{m}}$ & $2 \mathrm{~m} 2$ & 0 \\
$R_{\text {eff }}$ & $V_{r} / I_{i}^{C} V_{r}=1000 \mathrm{~V}$ & $56 \mathrm{~m} 2$ \\
$R_{s}$ & 0 & $2.8 \mathrm{~ms}$
\end{tabular}


TABLE III

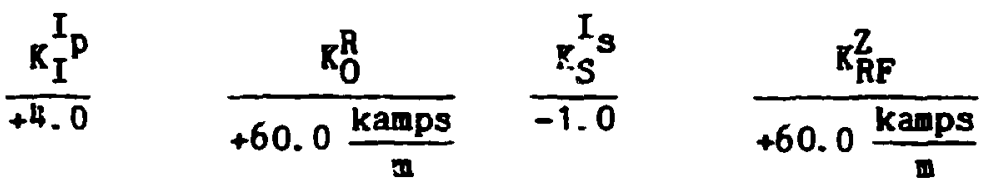

$$
\begin{aligned}
& \frac{\tau_{\mathrm{I}}^{I_{p}}}{5 \text { msec. }} \quad \frac{\tau_{0}^{R}}{5 \text { msec. }} \quad \frac{\tau_{s}^{I_{S}}}{5 \text { msec. }} \quad \frac{\tau_{\mathrm{RF}}^{Z}}{5 \text { msec. }}
\end{aligned}
$$

TABLE IV

\begin{tabular}{|c|c|c|}
\hline CASE & $\Delta \pi_{\mathrm{mx}}(\mathrm{cm})$ & $\Delta \mathrm{I}_{\mathrm{mx}}$ (kamps) \\
\hline $\bar{\beta}=.5$ to 18 in $20 \mathrm{msec}$ & 1 & 4 \\
\hline $\bar{B}=.5$ to 28 in $20 \mathrm{msec}$ & 4 & 13 \\
\hline $\bar{B}=.5$ to 58 in $50 \mathrm{msec}$ & 5 & 22 \\
\hline$R$ out $3 \mathrm{~cm}$. In $15 \mathrm{msec}$ & - & 0 \\
\hline$R$ in $3 \mathrm{~cm}$. in $10 \mathrm{msec}$ & - & 6 \\
\hline$I_{p}+10$ kamps in 20 maec & 0 & - \\
\hline$I_{p}-10$ kamps in 10 maec & 1 & - \\
\hline
\end{tabular}


TABLE V

$$
\bar{B}=.258
$$

$\frac{I_{s} \text { (kamps) }}{\varepsilon} \quad \frac{+5.0}{1.10} \quad \frac{+3.5}{1.15} \quad \frac{+2.5}{1.27} \quad \frac{+1.5}{1.27} \quad \frac{-.55}{1.55} \quad \frac{-1.1}{1.74}$

$$
\bar{B}=2.8 \%
$$

$\frac{I_{s} \text { (kamps) }}{\varepsilon}+\frac{0 .}{1.20} \quad \frac{-2.0}{1.27} \quad \frac{-2 .}{1.55} \quad \frac{1.74}{1.20}$ 


\section{REFEREACES}

[1] V. S. Mukovatov and V. D. Shafranov, Mucl. Fusion 11 (1971), p. 605 .

[2] N. Uckan - private commication.

[3] We wish to thank T. C. Tucker and Y-K. M. Peng for these results.

[4] We thank D. I Strickler and Y-K. M. Peng for providing the Grad-Shafranov results.

[5] We wish to thark R. J. Colchin who suggested this test.

[6] "Computer Solution of Ordinary Differential Equations: The Initial Value Problem," L. F. Shampine and M. K. Gordon, published by H. H. Freeman and Co.

[7] R. A. Dory and Y-K. M. Peng, Nuc1. Fusion 21 (1978).

[8] He wish to thank v. J. Strickler and Y-K. H. Peng for providing the results. 


\section{APPENDIX $A$}

The coefficients appearing in Eq. II-10 are

$$
\begin{aligned}
& A=\frac{-k_{2} \dot{\overline{\hat{D}}} \mathrm{C}^{-1}}{\mathrm{k}_{1} \mathrm{~B}_{\mathrm{v}} \mathrm{I}_{1}} \\
& B=\frac{-k_{2}}{k_{1} B_{v}} C^{-1} \text {. } \\
& \left.h_{1}=B\left\{\frac{2.1}{k_{2}}-\frac{\bar{B}}{I_{1}^{2}}\right\}-\frac{I_{1}{ }^{B}}{B_{v}} \mid \frac{2.1}{k_{2}}+\frac{\bar{\beta}}{I_{1}^{2}}\right\} f_{1}(R, Z), \\
& n_{i}=\frac{-I_{1}{ }^{B}}{B_{v}}\left|\frac{2.1}{k_{2}}+\frac{\overline{3}}{I_{1}^{2}}\right| f_{i}(R, 2) \text { it } 1 \text {, } \\
& D=\frac{-I_{1} B}{B_{v}} ; \frac{\mid 2.1}{k_{2}}+\frac{\sum_{i}}{I_{i}^{2}} \mid \sum_{i=1}^{7} \frac{\partial f_{i}(R, Z)}{\partial Z} I_{i} \text {, } \\
& C=1-\left[\frac{k_{2} I_{1}}{k_{1} B_{v}^{2}}\right]\left[\frac{2.1}{k_{2}}+\frac{\sum_{N}^{E}}{i_{1}^{2}}\right] \sum_{i=1}^{I} I_{i} \frac{\partial f_{i}(R, Z)}{\partial R} \text {, } \\
& k_{i}=-\frac{g_{i}\left(i, 7_{0}\right)}{F} \text {, } \\
& E=-\sum_{i=1}^{T} I_{i} \frac{\partial g_{i}(R, Z)}{\partial R} / F, \\
& F=\sum_{i=1}^{T} I_{i} \frac{\partial g_{i}(R, Z)}{\partial Z} .
\end{aligned}
$$

Quantities in the above not given here are defined i.s the teit. 
ORNL $/ C S D / T M-92$

\section{INTERNAL DISTEIEUTION}

1. H. P. Carter/A. A. Brooks/CSD Library

2-3. Central Research Library

4-13. L. A. Charlton

14. Document Reference Section - Y-12

15. R. A. Dory

16. R. H. Fowler

17-19. Laboratory Records

20. Laboratory Recr,rds - RC

21. G. H. Neilson

22. ORNL Fatent Office

23. D. W. Swain

\section{EXTERNAL DISTRIBUTION}

24. Chief, Mathematics and Gec science Branch, DOE, Washington, DC 20545

25. Office of Assistant Manager for Energy Research and Development, DOE/ORO, P.O. Box E, Oak Ridge, TN 37830

26. J. N. Rogers, Division 8324, Sandia Laboratories, I'vermore, IA 94550

27-53. Technical Information Center, P.0. Box 62, Oak Ricige, TN 37830 